Cahiers $d u$ MONDE RUSSE

\section{Cahiers du monde russe}

Russie - Empire russe - Union soviétique et États indépendants

$44 / 4 \mid 2003$

Varia

\title{
Peter Holquist, Making war, forging revolution
}

\section{Nathalie Moine}

\section{OpenEdition \\ Journals}

Édition électronique

URL : https://journals.openedition.org/monderusse/4104

DOI : 10.4000/monderusse.4104

ISSN : $1777-5388$

Éditeur

Éditions de l'EHESS

Édition imprimée

Date de publication : 1 octobre 2003

Pagination : 707-710

ISBN : 2-7132-1833-0

ISSN : $1252-6576$

Référence électronique

Nathalie Moine, "Peter Holquist, Making war, forging revolution », Cahiers du monde russe [En ligne], 44/4 | 2003, mis en ligne le 19 juin 2009, consulté le 04 septembre 2022. URL : http://

journals.openedition.org/monderusse/4104; DOI : https://doi.org/10.4000/monderusse.4104

Ce document a été généré automatiquement le 4 septembre 2022

Tous droits réservés 


\title{
Peter Holquist, Making war, forging revolution
}

\author{
Nathalie Moine
}

\section{RÉFÉRENCE}

Peter HOLQUIST, Making war, forging revolution. Russia's continuum of crisis, 1914-1921. Cambridge, MA, Harvard University Press, 2002, IX-359 p.

1 L'ouvrage de Peter Holquist doit se lire à plusieurs niveaux. Son premier objectif est de montrer la nécessité de réinscrire l'histoire de la révolution russe dans une histoire européenne. Il apporte donc une interprétation générale d'une séquence décisive de l'histoire russe et européenne, qui commence avec l'éclatement de la Première Guerre mondiale et s'achève avec la consolidation du régime bolchevik. Ainsi, l'année 1917, contrairement à ce que soutiennent les partisans comme les détracteurs de l'expérience révolutionnaire, ne constitue pas une rupture absolue, qui couperait définitivement la Russie du reste du continent, mais une année pivot, qui a, de fait, une influence déterminante sur la mobilisation finale et la séquence de crises traversée par le reste de l'Europe. Cependant, la mobilisation pour la guerre totale, les événements révolutionnaires, les guerres civiles - Holquist rappelant que les affrontements furent pluriels entre 1917 et 1921 - produisent des effets réciproques qui donnent un contour particulier au nouvel État bolchevik, pourtant issu d'une période de crise partagée par tous les pays combattants. Ce qui distingue dès lors l'État bolchevik des autres pays européens, aux yeux d'Holquist, c'est le maintien des méthodes de guerre dans un processus révolutionnaire permanent, même quand les conflits armés se sont tus, et que le projet révolutionnaire est devenu une orthodoxie. Au contraire de la Russie, dans les autres pays belligérants, les institutions qui étaient nées de la mobilisation de la société en temps de guerre, et constituaient des sortes d'appendices à des régimes politiques déjà existants, auraient été démantelées une fois la guerre achevée. Cependant, on peut déplorer que cette réaffirmation de la nécessaire inscription dans l'histoire européenne, qui participe d'un débat historiographique récurrent sur la nature de la révolution 
d'Octobre, soit davantage de l'ordre de l'affirmation que de la démonstration, faute d'une véritable comparaison terme à terme avec d'autres pays - exercice qui serait de toute façon fort problématique, du fait même de la diversité des expériences de guerre et, plus encore, des processus à l'œuvre dans l'après-guerre au sein des sociétés européennes.

2 En réalité, c'est à un autre niveau que s'articulent dans l'ouvrage de Holquist le cadrage théorique et la démonstration empirique. Au sein de cette expérience russe singulière, il œuvre en effet à un autre décloisonnement : celui de la culture politique des bolcheviks eux-mêmes. Le nouvel État qui naît d'Octobre ne doit se comprendre ni comme le pur produit de l'idéologie des bolcheviks, ni comme le seul fruit des événements des sept années terribles, de 1914 à 1921. Peter Holquist présente ce qu'il nomme un « modèle de développement télescopé » pour la Russie : celle-ci, à l'époque impériale, n’a pas vu se développer une société civile indépendante de l'État. Impuissante politiquement, elle n'en a que davantage nourri le sentiment d'être porteuse d'une mission civilisatrice, qui semble trouver sa voie à l'occasion des chamboulements de la guerre. De fait, société éduquée et pouvoir impérial - au moins dans sa composante réformatrice - tombent alors d'accord sur la nécessité de coopérer, construisant un appareil para-étatique qui prend en charge les grandes questions de la société en guerre. C'est donc dans la guerre que la société civile trouve à s'insérer dans des institutions nouvelles. À travers la question du ravitaillement, problème central de toutes les économies de guerre et qui deviendra emblématique de l'expérience soviétique, Peter Holquist suit la trace de cette collaboration qui entend exclure les structures commerciales, non sans un fort relent d'antisémitisme, et aboutit à une offre nettement insuffisante et au recours aux réquisitions forcées, avant même que les bolcheviks ne s'en mêlent. La révolution de 1917 ne fait que renforcer la croyance des milieux éduqués dans la nécessité du rôle de l'État pour contrôler la spontanéité du peuple et lui donner une éducation. Les anciens spécialistes de l'empire russe, même lorsqu'ils ne partagent pas le credo bolchevik, se rangent donc massivement du côté des nouvelles autorités.

De la même manière que la centralité de l'État n'est pas l'apanage des bolcheviks, l'approche révolutionnaire du changement social est largement partagée sur l'échiquier politique. Cette radicalité tient à la fois aux particularités déjà évoquées de la société civile embryonnaire de la fin de l'époque impériale, mais aussi, bien évidemment, aux circonstances. La révolution de 1917 entraîne une très forte politisation de part et d'autre. Les bolcheviks ne sont donc pas les seuls à recourir aux instruments de la propagande de masse pour gagner l'adhésion du plus grand nombre. Selon Holquist, c'est sans doute une des préoccupations les mieux partagées par les protagonistes du conflit européen, ainsi que les parties en conflit dans la Russie révolutionnaire, Rouges ou Blancs, et un des traits distinctifs d'un nouveau rapport aux populations mis en exergue par la guerre : la double préoccupation de forger l'opinion publique et de développer les instruments de sa surveillance à grande échelle. Les deux objectifs ont pour conséquence de mobiliser des deux côtés des membres de l'intelligentsia, mais aussi de convoquer l'armée, considérée comme le principal vecteur entre les tenants du pouvoir et le "peuple", faute d'autres structures comparables par exemple au puissant système d'instruction publique de la République française. Là encore, nulle part ailleurs que chez les bolcheviks, l'effacement de la frontière entre sphères civile et militaire et la politisation de la force armée ne sont aussi frappants, sans pour autant leur être propres.

Alors même que les individus semblent donc devenus des sujets politiques, la terreur de masse est elle aussi présente dans tous les camps. Le recours à la violence est 
omniprésent, même si les bolcheviks se trouvent très vite en mesure de la déployer de façon encore plus massive que leurs adversaires. Surtout, l'usage de la violence change chez eux de nature, à partir du moment où elle n'est pas seulement un instrument de domination mais aussi une arme de transformation de la société suivant les lignes de leur projet révolutionnaire.

Ce niveau d'interprétation de la séquence 1914-1921, qui s'attache à décrire convergences et divergences entre les parties en conflit au sein de l'échiquier politique russe, est, quant à lui, soigneusement étayé par une étude de terrain qui prend pour objet le territoire du Don. Prospère région agricole, celui-ci est un des principaux pourvoyeurs des exportations de l'empire, tout en comptant d'importants centres urbains et industriels, dont les mines du Donbass. Cependant, Peter Holquist s'est fait, pour le coup, modeste, et a décidé de ne se consacrer qu'au monde rural. C'est que, derrière ce choix, se cache l'enjeu principal de son étude : la forte présence d'une population cosaque, qui représente un peu moins de la moitié de la population du territoire du Don au recensement de 1897. De fait, c'est autour des enjeux de pouvoir représentés par les cosaques, mais aussi leurs propres formes de politisation, que s'incarnent les principales lignes d'interprétation que Holquist avait proposées d'emblée pour lire son récit.

Les sources convoquées sont impressionnantes par leur ampleur: archives centrales et régionales rendant compte de l'activité d'institutions gouvernementales, mais aussi du parti après octobre 1917, de nombreux fonds produits par les administrations des institutions cosaques et des mouvements contre-révolutionnaires, récupérés pour l'essentiel par les bolcheviks. Peter Holquist montre bien comment, à partir d'une situation sociale diverse - qui voit se côtoyer des officiers cosaques formés dans la capitale et des soldats du rang qui ont connu l'épreuve du feu, des grands propriétaires et de modestes paysans -, générant des engagements politiques tout aussi contrastés, se construit une identité cosaque qui finit par devenir synonyme de contre-révolution. Alors que la révolution de Février avait d'emblée aboli les états (soslovija) de l'Ancien Régime, Holquist retrace attentivement la reconstruction d'institutions cosaques et, à l'inverse, d'institutions qui les excluent de leurs rangs. La guerre des classes est brandie, les bolcheviks entendant s'appuyer sur les non-cosaques, dépeints comme les paysans pauvres, contre les cosaques, qui combineraient une aisance économique coupable et un état d'esprit contre-révolutionnaire. La campagne de décosaquisation du début de l'année 1919 constitue l'apogée de cette construction d'un groupe en une catégorie compacte qu'il s'agit d'éliminer, au moins en partie physiquement, non pas seulement sur la base des actes commis par les individus, mais en fonction de l'identité qui leur a été assignée. Peter Holquist dégage ainsi un mécanisme qui sera reproduit à plusieurs reprises dans l'histoire soviétique, du fait même du fonctionnement de la violence comme politique d'État pour réaliser son schéma révolutionnaire. Il est alors important de souligner le caractère centralisé de cette évolution de la violence, qui n'est pas le fait, en premier lieu, des autorités locales. En même temps, l'auteur souligne qu'on ne peut parler de génocide : la violence exacerbée constitue un moment politique qui retombe, lorsque le centre décide d'y mettre fin, pour un temps.

7 Le récit d'Holquist s'achève sur la double vision d'une révolution consolidée, devenue une pensée officielle soutenue par une violence institutionnalisée, et d'un territoire du Don ravagé par les guerres, la famine, et qui a perdu son statut de grenier de la Russie, à l'orée d'un nouveau cycle de violence après l'accalmie de la NEP. 
8 Le récit d'Holquist s'achève sur la double vision d'une révolution consolidée, devenue pensée officielle, soutenue par une violence institutionnalisée, mais ayant perdu pour l'essentiel un soutien populaire, et d'un territoire du Don ravagé par les guerres, les révoltes écrasées dans le sang, les réquisitions forcées conduisant tout droit à la terrible famine de 1921-1922. Holquist rappelle que la NEP, prise au sens de période d'accalmie, commence pour le moins tardivement dans la région du Don, l'ancien grenier à blé de la Russie, à l'orée d'un nouveau cycle de violence avec la collectivisation et la dékoulakisation.

9 Selon ses goûts et ses préférences méthodologiques, le lecteur appréciera surtout les analyses minutieuses d'un champ régional particulier, qui ouvre de nombreuses pistes permettant d'entrer dans le détail du processus révolutionnaire, ou plutôt les montées en généralité, le plus souvent séduisantes, mais parfois vacillantes sur le plan de la démonstration. La fécondité de cette recherche, qui a déjà fait date, était sans doute à ce prix. 